\title{
Effect of Computer Multimedia Assisted Word Annotation on Incidental Vocabulary Acquisition of English Reading
}

\author{
https://doi.org/10.3991/ijet.v14i13.10705 \\ Mengqing Han \\ Shijiazhuang University of Applied Technology, Shijiazhuang, China \\ Shanshan Niu $(\bowtie)$ \\ Huaxin College of Hebei GEO University, Shijiazhuang, China \\ 360018500 @qq. com
}

\begin{abstract}
This paper aims at researching the effect of computer multimedia assisted word annotation on incidental vocabulary acquisition of English reading of Chinese students. An empirical research experiment is designed based on the ideas of word annotation, incidental vocabulary acquisition, multimedia annotation, and so on. Through analyzing, three main problems are put forward in this paper. In the empirical experiment, two variables of different annotation modes and subjects' English levels are designed and immediate test and delayed test are adopted. By selecting suitable test subjects, test materials and test tool, an empirical research has been conducted and the corresponding conclusions have been drawn. The re-search takes the effect of individual English level differences on incidental vocabulary acquisition of English reading and the experimental result play a positive role in the selection of suitable computer assisted annotation modes for students of different English levels.
\end{abstract}

Keywords - Computer multimedia, word annotation, incidental vocabulary acquisition, empirical research

\section{$1 \quad$ Introduction}

English vocabulary is the cornerstone of English learning and the level of English vocabulary is related to the levels of all aspects, such as English listening, speaking, reading and writing. Researches show that the learning of English vocabulary is not only obtained through English vocabulary teaching, but can be acquired in incidental acquisition by various learning modes, such as English reading, English listening comprehension, and English writing. Incidental vocabulary acquisition in English reading is the main mode of indirect learning of vocabulary and the research focus. It is often thought that vocabulary annotation in English reading can increase the incidental vocabulary acquisition. Recently, with the popularity of computer assisted learning $(\mathrm{CAL})$ in English learning applications, computer multimedia assisted word 
annotation has been widely used in English teaching so as to improve students' English reading efficiency and incidental vocabulary acquisition [1-3].

The concept of incidental vocabulary acquisition of second language at abroad was put forward and researched as early as 1985 . Some scholars have concluded that the multimedia annotation mode combining text and language can better promote the incidental vocabulary acquisition than the single text annotation. Some scholars have proved the positive role of multimedia annotation in language learning and language teaching through experiments. Compared with the mature second language learning annotation research at abroad, the research on the computer as ancillary equipment for multimedia assisted annotation at home is still in its infancy. Relevant scholars have conducted studies by referring to the overseas researches on multimedia annotation and incidental vocabulary acquisition, and made a comparative research on four kinds of multimedia annotations, including Chinese annotation, English annotation, Chinese plus pictures, English plus pictures, as well as drawn a conclusion that the annotation effect of Chinese plus pictures is the best. Although researches at home have made great progress, computer multimedia assisted word annotation hasn't considered the key variable-learners' English levels, and research on voice assisted annotation as a part of multimedia annotation has been seldom studied [4-6].

This paper first interprets and analyzes the related concepts and shows different modes of multimedia assisted word annotation, which lays a solid theoretical foundation for experimental research. In the experimental demonstration phase, three main problems are clarified and variables of different annotation modes and subjects' English levels are set. Annotation modes include text + picture, text + voice, text + picture + voice and subjects' English levels include high and low levels. 105 students from a normal university are chosen as experimental subjects. Then this paper adopts immediate test and delayed test, designs test materials, test tool, and experimentation, as well as analyzes the experimental result. This research considers the effect of multimedia vocabulary annotation on incidental vocabulary acquisition at different English levels, and applies the voice as a multimedia assisted annotation to the empirical research. The research results are of great significance to the application of multimedia assisted annotation in English reading, which can help students improve incidental vocabulary acquisition in reading.

\section{Theoretical Basis}

\subsection{Incidental vocabulary acquisition}

Concept definition: The term "incidental vocabulary acquisition" was first proposed in 1985, holding that children did not intentionally acquire vocabulary of their mother tongue but learned the vocabulary from incidental acquisition in other tasks, such as reading, listening to songs and retelling. Vocabulary learning can be divided into direct vocabulary learning and indirect vocabulary learning. The former refers to various forms of direct vocabulary learning while the latter refers to the incidental vocabulary acquisition in the process of focusing on speech transmission and reading 
comprehension. Why vocabulary is "incidental" is because learners' main attention and learning materials are not vocabulary learning but learning the vocabulary incidentally on the basis of comprehending and having a full grasp of the full text. Although no unified definition of incidental vocabulary acquisition has been formed in the field of second language researches, second language researchers in many fields think that incidental vocabulary acquisition plays an important role in second language learning [7-8].

Influencing factors: Through the research of scholars in the industry, the following five factors that affecting the incidental vocabulary acquisition are summarized:

- The vocabulary of the learner, the research indicates the premise of vocabulary incidental acquisition is that the learner's foreign language vocabulary is greater than 2000, especially in English reading only by mastering most of the vocabulary can learner build contextual knowledge and successfully guess the meaning of words;

- The familiarity of the topic and the ability of the learner to read, experimental research shows that the familiarity of the topic is proportional to the reader's ability and the ability of the new words to be acquired;

- The frequency occurrence of vocabulary in the reading material, the higher the frequency of vocabulary appearing in the reading article, the better the vocabulary incidental acquisition effect;

- The learner's ability to guess words, students with good guessing ability, can learn more new words in reading, they are more likely to expand their vocabulary than students with poor guessing ability, the learner's ability to guess words does have a certain impact on vocabulary incidental acquisition, learners with stronger guessing ability have better vocabulary learning effect;

- The amount of input by the learner, the self-review of the learner after reading the task is considered as the input of vocabulary incidental acquisition, the more the input, the better the learned effect and the longer vocabulary memory [9-10].

\subsection{Annotation}

Concept definition: Some scholars think that the word "annotation" can date back to the Middle Ages when students learned foreign language articles usually in Latin and annotation could help students better interpret the article. Traditionally, annotations are placed at the margin or footer to help students understand the meaning of the article so that the reading process won't be interrupted for looking up dictionaries. Second language learning annotations can be divided into mother tongue annotation, second language annotation and bilingual annotation from the annotation language; can be divided into individual annotation and multiple annotations in terms of annotation form; and can be divided into multimedia annotation and plain text annotation from the annotation modes. With the development of computer multimedia technology, multimedia annotation methods based on pictures, voice and videos have become more and more popular [11-12]. 
Multimedia annotation: Because of the close connection between annotation and second-language reading comprehension, vocabulary acquisition, the current research on annotations only discusses annotations as an incidental content of reading and vocabulary, and does not form an independent theoretical system supporting multimedia annotations. Therefore, most of the theories of annotation research are based on the two-language reading comprehension and vocabulary acquisition theory. The existing annotation-related theories include Schimdt's attention theory, Wittrock's production processing theory, and Paivio's double-coding theory. Among them, double-coding theory is the most widely used in second language acquisition.

Double-coding Theory holds that the human memory system contains two independent but interrelated information processing code systems: language system and non-language system. The language system processes the language code and stores the language information while the non-language system processes the non-language factors, such as images, emotional response and visual pictures. Compared words that are processed only by language system, word that are processed simultaneously by both language and non-language systems are better understood and memorized for learners [13-14].

Based on Double-coding Theory, multimedia annotation mode conducts short definition or explanation for new words through texts, pictures, voice, videos and other non-linguistic ways. With the popularity of computer hardware technology, the mode of multimedia assisted word annotation has been widely used in English reading teaching. The study of multimedia annotation to improve students' reading comprehension and to increase students' incidental vocabulary acquisition has become a research hotspot [15].

\section{Application of Computer Multimedia Annotation in English Reading}

\subsection{Practical cases of English reading-Text annotation}

The application of computer multimedia technology in English reading tends to be mature in China. An excerpt of reading comprehension is chosen from intensive reading course of College English. As shown in Figure 1, it is a case of text annotation of computer multimedia technology in English reading. 
58 My basic advice is simple and heartfelt: Get the best education you can Iake advantage of high school and college. Learn how to learn. प

18 It's true that I dropped out of college to start Microsoft, but I was at Harvard for three years before dropping out and $I^{\prime} d$ love to have the time to go back. As I've said before, nobody should drop out of college unless they believe they face the opportunity of a lifetime. And even then they should reconsider. W

Fig. 1. Case of text annotation of computer multimedia technology in English reading

In Figure 1, the corresponding annotation can be seen when clicking on the underlined keywords. Multimedia annotation makes it more convenient for students to complete the overall reading and saves time, which achieves efficient and concise English reading. Besides, incidental acquisition of key new words is also achieved in the reading [16].

\subsection{Practical cases of English readingpicture annotation}

In addition to text annotation, hypermedia technology also brings picture annotation. The following excerpt contains four words "Valley", "Plain", "Instrument", and "Freeze" from reading text. It is supposed that these words are unfamiliar to the learners and the corresponding text annotation can't make the learners understand their meaning. Then multimedia technology can be used to help learners understand the meaning of words in the form of pictures as shown in Figure 2.

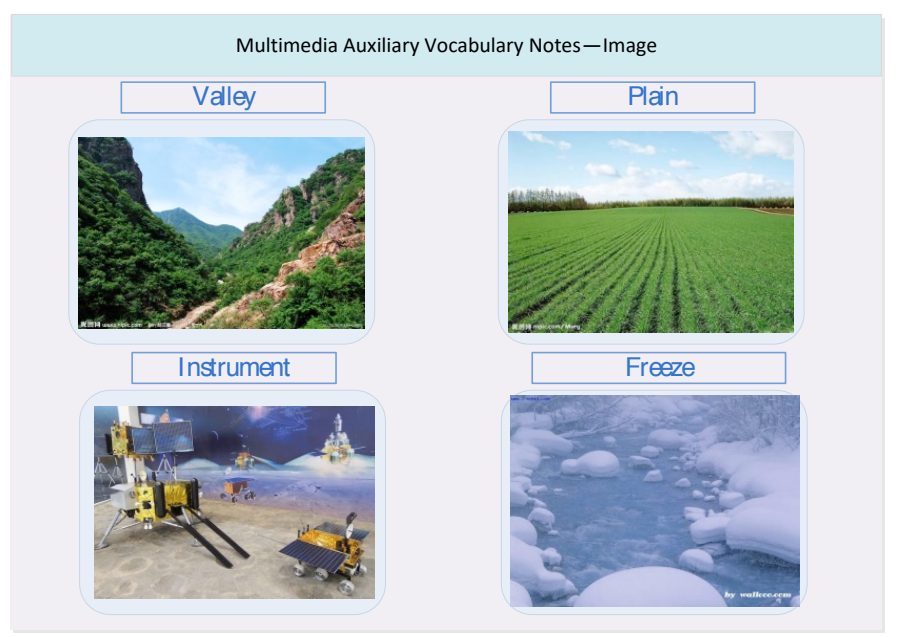

Fig. 2. Picture annotation 
In addition to individual annotations of pictures and texts, computer hypermedia technology has achieved combined annotation of vocabulary in English reading. Next, we will demonstrate the effect of these different types of annotations on incidental vocabulary acquisition by specific examples [17].

\section{Effect of Computer Multimedia Assisted Word Annotation}

\subsection{Empirical research questions}

In view of the status quo of researches and the purpose of this study in China, it is necessary to clarify the following questions in empirical experiments:

- Do the different annotations have an effect on incidental vocabulary acquisition in reading comprehension? Is the effect related to learners' English levels?

- Which kind of multimedia annotation mode can best promote incidental acquisition of English vocabulary and whether is related to the English levels of learners?

- Which kind of multimedia annotation mode is best for learners to deepen their vocabulary memory and whether it is related to the English levels of learners?

\subsection{Empirical research methods}

Experimental group design: There are two groups of variables in this research, namely annotation mode of and English levels. The annotation modes include text + picture, text + voice, text + picture + voice and English levels include high and low levels. Therefore, the experiment can be divided into six groups.

105 students of non-English major from a normal university are chosen as experimental subjects. Before the test, the language level assessment is used to test students' vocabulary. According to the results of the vocabulary test, among 105 students, 53 are at high level and 52 are at low level. The specific grouping of test is text + picture (18 at high level and 19 at low level), text + voice (17 at high level and 18 at low level, text + picture + voice (18 at high level and 15 at low level).

Experimental material of reading: It is very crucial to select reading materials and the difficulty level should be equivalent to the English levels of subjects. In this paper, Seven Crows in Grimm's Fairy Tales is taken as the experimental material whose Forecast reading index is 7.8 and the difficulty is moderate. 18 new words are chosen from it as target learning words. The method of multimedia courseware annotation is used to annotate the target words: the words are given the meaning through English-Chinese Dictionary in form of text; the related pictures are retrieved through the Internet; and the pronunciation is recorded and explained by the English professional teachers.

Test tool: The test tool refers to the test item types for testing students' level of incidental vocabulary acquisition. The first one is analysis of word meanings which requires students to write down the meaning of the 18 target words in Chinese or English with a total of 18 points. The second one is gap filling. Students will select 
1six words for different contexts and scenarios from the 18 target words to fill in the blank with a total of 1 six points. The test tool takes into account both the productive ability and receptive ability of incidental vocabulary acquisition.

\section{Experimentation}

- Experimental setting: Learning task is introduced first and reading test materials for six groups of students are prepared. Students are required to complete analysis of word meanings and gap filling. The test time is 40 minutes.

- Immediate vocabulary test: After the completion of the 40-minute test, six groups of students are required to take immediate test for 18 target words to check incidental vocabulary acquisition for 15 minutes.

- Delayed vocabulary test: Two weeks after completing the immediate test, only the order of the vocabulary test questions is changed to test the incidental vocabulary acquisition again.

- SPSS11.0 is used to count six kinds of test scores of immediate vocabulary test and delayed vocabulary test.

\subsection{Analysis and discussion of research results}

Research results: Table 1 is the scores statistics of immediate vocabulary test and delayed vocabulary test of six groups of students, including the average score and standard deviation.

Table 1. Vocabulary test scores statistics of six groups of students

\begin{tabular}{|c|c|c|c|c|c|c|}
\hline \multirow{3}{*}{$\begin{array}{c}\text { English } \\
\text { level }\end{array}$} & \multirow{3}{*}{ Annotation } & \multirow{3}{*}{ Number } & \multicolumn{4}{|c|}{ Instant test } \\
\hline & & & \multicolumn{2}{|c|}{ Meaning } & \multicolumn{2}{|c|}{ Gap filling } \\
\hline & & & Average & $\begin{array}{c}\text { Std } \\
\text { deviation }\end{array}$ & Average & $\begin{array}{c}\text { Std } \\
\text { deviation }\end{array}$ \\
\hline \multirow{3}{*}{ High level } & Text+Image & 18 & 4.11 & 3.802 & 4.06 & 2.578 \\
\hline & Text+Voice & 17 & 6.82 & .557 & 5.88 & 4.167 \\
\hline & Text+Image +Voice & 18 & 8.56 & 4.681 & 8.33 & 4.087 \\
\hline \multirow{3}{*}{ Low level } & Text+Image & 19 & 2.95 & 2.972 & 2.53 & 2.010 \\
\hline & Text+Voice & 18 & 5.17 & 4.423 & 5.33 & 3.464 \\
\hline & Text+Image +Voice & 15 & 4.33 & 3.436 & 4.13 & 2.503 \\
\hline \multirow{3}{*}{$\begin{array}{c}\text { English } \\
\text { level }\end{array}$} & \multirow{3}{*}{ Annotation } & \multirow{3}{*}{ Number } & \multicolumn{4}{|c|}{ Delay test } \\
\hline & & & \multicolumn{2}{|c|}{ Meaning } & \multicolumn{2}{|c|}{ Gap filling } \\
\hline & & & Average & $\begin{array}{c}\text { Std } \\
\text { deviation }\end{array}$ & Average & $\begin{array}{c}\text { Std } \\
\text { deviation }\end{array}$ \\
\hline \multirow{3}{*}{ High level } & Text+Image & 18 & 1.94 & 2.100 & 1.61 & 1.577 \\
\hline & Text+Voice & 17 & 3.35 & 2.783 & 4.06 & 3.288 \\
\hline & Text+Image +Voice & 18 & 3.33 & 2.679 & 4.33 & 3.308 \\
\hline \multirow{3}{*}{ Low level } & Text+Image & 19 & 1.37 & 1.499 & 2.05 & 1.649 \\
\hline & Text+Voice & 18 & 1.28 & 1.841 & 2.33 & 2.910 \\
\hline & Text+Image +Voice & 15 & 1.53 & 1.727 & 3.67 & 1.952 \\
\hline
\end{tabular}

It can be seen from the table that for subjects of high English levels, the average score of text + picture + voice annotation mode is the highest in the three kinds of annotation modes both in immediate and delayed test followed by text + voice annotation mode. And the average score of text + picture annotation mode is the lowest. For 
subjects of low English levels, the average score of analysis of word meanings and gap filling of text + voice annotation mode in immediate test is the highest and the average score of text + picture + picture annotation mode in delayed test is the highest.

In order to further observe the effect of three kinds of annotation modes on incidental vocabulary acquisition, one-dimensional analysis of variance is carried out and the results are shown in Table 2 (a) and Table 2 (b).

Table 2. (a) One-dimensional analysis of variance results

\begin{tabular}{|c|c|c|c|c|c|c|}
\hline & & \multirow[b]{2}{*}{ Test level } & \multicolumn{2}{|c|}{ Quadratic sum } & \multicolumn{2}{|c|}{ DOF } \\
\hline & & & High & Low & High & Low \\
\hline \multirow{4}{*}{ Instant test } & \multirow{2}{*}{ Meaning } & Between-group & 180.552 & 46.527 & 2 & 2 \\
\hline & & intra-group & 820.693 & 656.781 & 50 & 49 \\
\hline & \multirow{2}{*}{ Gap filling } & Between-group & 165.819 & 73.453 & 2 & 2 \\
\hline & & intra-group & 674.709 & 364.470 & 50 & 49 \\
\hline \multirow{4}{*}{ Delay test } & \multirow{2}{*}{ Meaning } & Between-group & 23.240 & 0.542 & 2 & 2 \\
\hline & & intra-group & 320.827 & 139.765 & 50 & 49 \\
\hline & \multirow{2}{*}{ Gap filling } & Between-group & 80.328 & 24.027 & 2 & 2 \\
\hline & & Intra-group & 401.219 & 246.281 & 50 & 49 \\
\hline
\end{tabular}

(b) One-dimensional analysis of variance results

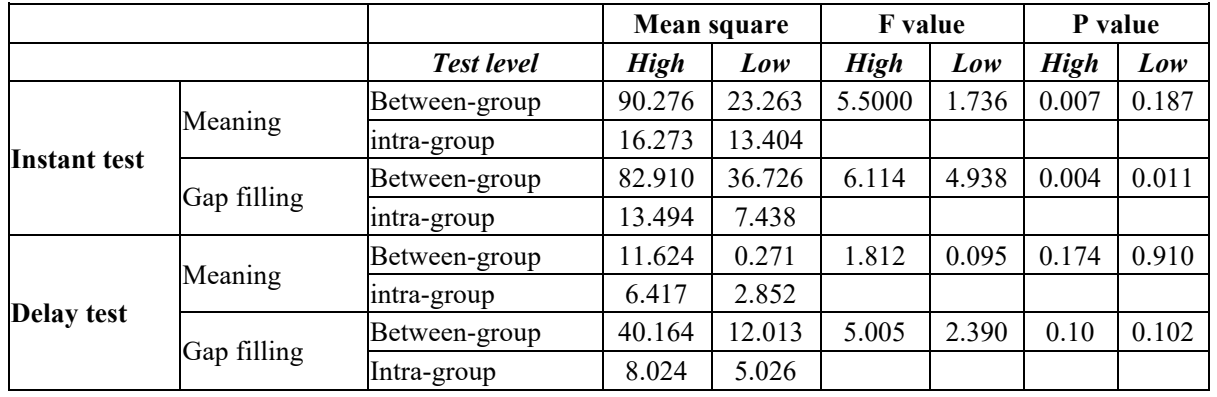

It can be seen from the table that there is a significant difference $(\mathrm{P}<0.5)$ in analysis of word meanings test results of different annotation modes in immediate or delayed tests for high-level English learners, and it is the same with low-level English learners.

Based on the one-way variance results of Table 2, the Scheffé test is used to test the impact of the three annotation methods on reading and vocabulary tasks [18-19]. The main research results are as shown in Table 3 (a) and Table 3 (b). 
Table 3. (a) The effect of three annotations on the vocabulary test of high and low level learners

\begin{tabular}{|c|c|c|c|}
\hline Tester & dependent variable & Inde & ariable \\
\hline- & - & Annotations 1 & Annotations 2 \\
\hline \multirow{6}{*}{ High level } & \multirow{3}{*}{ Instant test } & Text+image & Text+voice \\
\hline & & Text+image & Text+voice+image \\
\hline & & Text+voice & Text+voice+image \\
\hline & \multirow{3}{*}{ Delay test } & Text+image & Text+voice \\
\hline & & Text+image & Text+voice+image \\
\hline & & Text+voice & Text+voice+image \\
\hline \multirow{6}{*}{ Low level } & \multirow{2}{*}{ Instant test } & Text+image & Text+voice \\
\hline & & Text+image & Text+voice+image \\
\hline & & Text+voice & Text+voice+image \\
\hline & \multirow{3}{*}{ Delay test } & Text+image & Text+voice \\
\hline & & Text+image & Text+voice+image \\
\hline & & Text+voice & Text+voice+image \\
\hline
\end{tabular}

(b) The effect of three annotations on the vocabulary test of high and low level learners

\begin{tabular}{|c|c|c|c|c|c|c|c|}
\hline Tester & dependent & \multicolumn{3}{|c|}{ Mean difference (1-2) } & \multicolumn{3}{|c|}{$P$ value } \\
\hline- & - & Reading & Meaning & $\begin{array}{c}\text { Gap- } \\
\text { filling }\end{array}$ & Reading & Meaning & $\begin{array}{c}\text { Gap- } \\
\text { filling }\end{array}$ \\
\hline \multirow{6}{*}{ High level } & \multirow{3}{*}{ Instant test } & 0.061 & -2.74 & -1.82 & 0.968 & 0.158 & 0.324 \\
\hline & & -0.061 & $-4.48^{*}$ & $-4.38 *$ & 0.992 & 0.0075 & 0.0048 \\
\hline & & -0.113 & -1.704 & -2.43 & 0.978 & 0.453 & 0.152 \\
\hline & \multirow{3}{*}{ Delay test } & - & -1.41 & $-2.45^{*}$ & - & 0.268 & 0.0467 \\
\hline & & - & -1.38 & $-2.71 *$ & _- & 0.267 & 0.46 \\
\hline & & - & -0.021 & -0.272 & - & 1.002 & 0.956 \\
\hline \multirow{6}{*}{ Low level } & \multirow{2}{*}{ Instant test } & 0.174 & -2.20 & $-2.81 *$ & 0.953 & 0.193 & 0.011 \\
\hline & & $2.15^{*}$ & -1.39 & -1.61 & 0.0021 & 0.551 & 0.241 \\
\hline & & $1.98 *$ & 0.82 & 1.21 & 0.0065 & 0.814 & 0.455 \\
\hline & \multirow{2}{*}{ Delay test } & - & 0.098 & -0.278 & - & 0.998 & 0.931 \\
\hline & & - & -0.16 & -1.61 & - & 0.962 & 0.124 \\
\hline & & - & -0.26 & -1.34 & - & 0.910 & 0.243 \\
\hline
\end{tabular}

The results show that in the instant test for high level learner, the text + image + voice annotation in the meaning task is significantly different from the text + image annotation. There is also a significant difference in the gap filling task. In the delay test, there is no significant difference in the form of annotation in the meaning task, but the text + voice annotation, the text + image + voice annotation and the text + image annotation has significantly different in the gap-filling task. The test results show that the text + image +voice annotation promote vocabulary learning more than the text + image annotation. The text + voice annotation and the text + image + voice annotation is more conducive to vocabulary memory reservation than the text + image annotation.

Meanwhile, it can be seen from the table that there are significant differences in the test results of the three annotation methods in the low-level English learners' reading 
tasks in the instant test; there is no significant difference in the text meaning test, and there is a significant difference between the text + voice and the text + image of the gap-filling task; there are no significant differences in the three annotations in the delay test.

Analysis and discussion: This paper studies the effect of different annotation modes on incidental vocabulary acquisition of English learners at different levels. The results show that, for high-level learners, text + picture + voice annotation mode can better promote incidental vocabulary learning than text + picture while there is no significant difference for low-level learners. According to the analysis, the voice is the pronunciation and spelling of new words and their example sentences, which spends so much time that students can't grasp new words. For low-level English learners, voice annotation is not effective for the fast speed of pronunciation that exceeds the hearing ability of subjects while voice annotation is more beneficial to highlevel English learners to master vocabulary than text + picture annotation.

The experimental results also show that, for low-level learners, the effect of text + voice annotation in gap filling task is better than the text + picture annotation, indicating that the combination annotation of text and voice is better than the combination annotation of text and picture. This may be because voice is related to phoneme and spelling of words. Thus, text and voice can promote the combination of the meanings and forms of words while text and picture only highlight the meaning. Therefore, the promotion effect of text + picture annotation on incidental vocabulary acquisition is not as good as that of text + voice annotation or text + picture + voice annotation.

Research implications: In vocabulary learning, learners should pay attention to the combination of multimedia and should be good at using the multimedia learning environment to link language information with non-verbal information, so as to deepen the understanding and memory of vocabulary more effectively and achieve better results. learning result.

Teachers should use multimedia to teach vocabulary, which is more effective than just presenting abstract words. For low-level English learners, the combination of text and drawing combinations, especially the combination of Chinese characters and drawings, is most beneficial for their vocabulary learning.

In the production of multimedia courseware, the matching method of filling mode and different processing modes should be considered to adapt to different learning needs.

\section{Conclusion}

Incidental vocabulary acquisition is an effective way of vocabulary learning. At present, the study of incidental vocabulary acquisition in reading comprehension has become a research hotspot. This paper researches the effect of computer multimedia assisted word annotation on incidental vocabulary acquisition of English reading and conducts relevant empirical studies. This paper first expounds the related concepts, puts forward the main problems, and completes the empirical research experiment by 
setting reasonable experimental contents. This paper has the following conclusions and expectations:

- Different modes of annotation all have a positive effect on the incidental vocabulary acquisition, and this effect is related to learners' English levels

- For high-level learners, the effect of text + picture + voice annotation mode is the best while text + voice annotation mode is the best for low-level learners. Text + picture + voice annotation mode is more conducive to long-term memory and the retention of vocabulary.

- In English teaching, the application of multimedia assisted annotation in reading should be strengthened so that learners can achieve incidental vocabulary learning and mastery in reading.

\section{$6 \quad$ References}

[1] Wijayanti, D. (2013). The vocabulary mastery of the elementary level students of the center of English language learning (cell) course pati in academic year 2012/2013 taught by using interactive power point games. Skripsi. Experimental Gerontology, 42(8): 713-718.

[2] Mohammadi, H. (2014). Psychological construct and English vocabulary learning: a structural equation modeling approach. International Mathematics Research Notices, (8): 12691281. http://dx.doi.org/10.1155/S1073792896000268

[3] Laufer, M.H.B. (2005). Type of task, time-on-task and electronic dictionaries in incidental vocabulary acquisition: iral - international review of applied linguistics in language teaching. Journal of Medical Genetics, 42(10): 774-779.

[4] McGraw, I., Yoshimoto, B., Seneff, S. (2009). Speech-enabled card games for incidental vocabulary acquisition in a foreign language. Speech Communication, 51(10): 1006-1023. http://dx.doi.org/10.1016/j.specom.2009.04.011

[5] Zhang, S., Li, B., Xue, X. (2010). Semi-automatic dynamic auxiliary-tag-aided image annotation. Pattern Recognition, 43(2): 470-477. http://dx.doi.org/10.101 6/i.patcog.2009.03.009

[6] Weston, J., Bengio, S., Usunier, N. (2010). Large scale image annotation: learning to rank with joint word-image embeddings. Machine Learning, 81(1): 21-35. http://dx.doi.org/10. 1007/s10994-010-5198-3

[7] Bisson, M.J., Heuven, W.J.B.V., Conklin, K., Tunney, R.J. (2015). The role of verbal and pictorial information in multimodal incidental acquisition of foreign language vocabulary. Quarterly Journal of Experimental Psychology, 68(7): 1306-1306. http://dx.doi.org/10. $\underline{1080 / 17470218.2014 .979211}$

[8] Heidari-Shahreza, M.A. (2014). The effect of 11-12 lexicalization mismatch on incidental acquisition of receptive vocabulary knowledge. Journal of Virology, 39(19): 67-76.

[9] Ricketts, J., Bishop, D.V.M., Nation, K. (2009). Orthographic facilitation in oral vocabulary acquisition. The Quarterly Journal of Experimental Psychology, 62(10), 1948-1966. http://dx.doi.org/10.1080/17470210802696104

[10] Stevens, W.D., Hasher, L., Chiew, K.S., Grady, C.L. (2008). A neural mechanism underlying memory failure in older adults. Journal of Neuroscience, 28(48), 12820-12824. http://dx.doi.org/10.1523/JNEUROSCI.2622-08.2008

[11] Darula, Z., Chalkley, R. J., Baker, P., Burlingame, A.L., Medzihradszky, K.F. (2010). Mass spectrometric analysis, automated identification and complete annotation of o-linked 
Paper-Effect of Computer Multimedia Assisted Word Annotation on Incidental Vocabulary...

glycopeptides. European Journal of Mass Spectrometry, 16(3): 421-428. http://dx.doi.org/10.1255/ejms.1028

[12] Ferragina, P., Scaiella, U. (2011). Fast and accurate annotation of short texts with wikipedia pages. IEEE Software, 29(1): 70-75. http://dx.doi.org/10.1109/ms.2011.122

[13] Krallinger, M., Leitner, F., Rodriguez-Penagos, C., Valencia, A. (2008). Overview of the protein-protein interaction annotation extraction task of biocreative ii. Genome Biology, 9(Suppl 2): S4-S4. http://dx.doi.org/10.1186/gb-2008-9-s2-s4

[14] Organization, W.H. (2014). Who media centre: collection of who news releases, notes for the media, statements, events, fact sheets, multimedia. Journal of Cell Science, 127(Pt19): 4172-4185.

[15] Santoni, R., Cellai, E. (1995). Technical note: multimedia clinical records: results of a pilot project at the radiation therapy department of Florence. British Journal of Radiology, 68(808): 413-20. http://dx.doi.org/10.1259/0007-1285-68-808-413

[16] Nagao, K., Shirai, Y., Squire, K. (2001). Semantic annotation and transcoding: making text and multimedia contents more usable on the web. IEEE Multimedia, 8(2): 69-81. http://dx.doi.org/10.1109/93.917973

[17] Stamou, G., Ossenbruggen, J.V., Pan, J.Z., Schreiber, G. (2006). Multimedia annotations on the semantic web. IEEE Multimedia, 13(1): 86-90. http://dx.doi.org/ $10.1109 / \mathrm{mmul} .2006 .15$

[18] Alexander, B.T. (2003). Placental insufficiency leads to development of hypertension in growth-restricted offspring. Hypertension, 41(3): 457-462. http://dx.doi.org/10.116 1/01.HYP.0000053448.95913.3D

[19] Erk, M., Ivanković, D., Raspor, B., Pavicić, J. (2002). Evaluation of different purification procedures for the electrochemical quantification of mussel metallothioneins. Talanta, 57(6): 1211-1218. http://dx.doi.org/10.1016/S0039-9140(02)00239-4

\section{$7 \quad$ Authors}

Mengqing Han graduated from North China University of Science and Technology with a master's degree in English interpretation, now is an English teacher from Shijiazhuang University of Applied Technology. Her main research direction is English teaching, English translation, English language and literature.

Shanshan Niu graduated from North China University of Science and Technology with a master's degree in English translation, now is an English teacher from Huaxin College of Hebei GEO University. Her main research direction is English teaching, English translation, English literature and intercultural communication.

Article submitted 2019-04-19. Resubmitted 2019-06-13. Final acceptance 2019-06-27. Final version published as submitted by the authors. 